
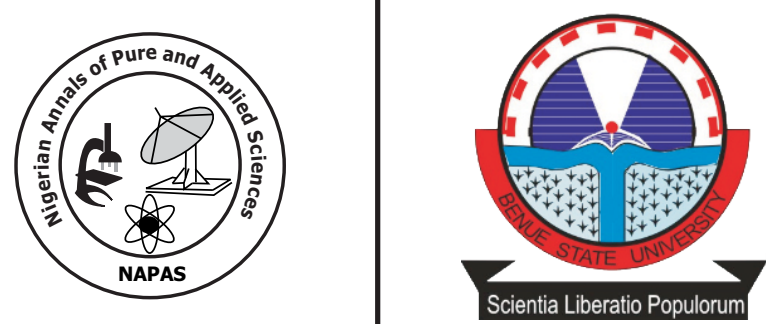

\title{
Prevalence of Urinary Schistosomiasis among primary school children in three rural communities of Kano State, Nigeria
}

\author{
${ }^{1,3}$ Department of Biological sciences, \\ Nigeria Police Academy Wudil, Kano State Nigeria \\ ${ }^{2,4}$ Department of Forensic science, \\ Nigeria Police Academy Wudil, Kano State Nigeria \\ *Correspondent author: Duwa, R.S
}

${ }^{1 *}$ Duwa, R. S., ${ }^{2}$ Sanusi, A., ${ }^{3}$ Ogbunachara, C and ${ }^{4}$ Okiemute, F.

\section{Abstract}

This study was carried out among pupils of three primary schools in Dawakin Kudu Local Government Area of Kano State, Nigeria between May and July, 2018. Three hundred and twenty (320) pupils were examined for the presence of schistosome eggs in urine. Out of the 320 pupils examined only $34(10.6 \%)$ were found to be infected with S haematobium. Males have higher prevalence of $26(12.1 \%)$ compared to females $8(7.6 \%)$. The age group $8-10$ years has the highest infection rate $13(15.85 \%)$ while the age group 5-7 the least with 1(4.6\%). Although sample sizes were not equal, among the communities Fallau with 65 has the highest infection rate with a prevalence of 11(16.9\%), Gano with 135 has $14(10.4 \%)$ followed by Danbagina, 120 with a prevalence of $9(7.5 \%)$. All infections were light $(<50 \mathrm{eggs} / 10 \mathrm{ml}$ of urine $)$. There was a significant difference in infection among the different villages examined $\chi^{2}=8.94, \mathrm{df}=2$, $\mathrm{p}<0.05$. Statistically there was also a significant difference in infection among the different age groups $\chi^{2}=$ 2.9356 , df $=3, \mathrm{p}<0.05$. It was concluded that $S$. haematobium is present in these study areas and unless health education on the mode of transmission of the disease, provision of safe and adequate water supply and sanitation which will help in curtailing the infection is provided, there is the likelihood of a rise in infection rate. This is the first time this type of study was carried out in these study areas.

Key words: Urinary schistosomiasis, Kano state, Prevalence, School children, Wudil River 


\section{Introduction}

Urinary and intestinal Schistosomiasis becomes a major public health problem and was rated second to malaria in terms of socioeconomic and public health impact as the most devastating parasitic disease in tropical countries (CDC, 2004). While at least 258 million requires preventive treatment for schistosomiasis in 2014 more than 61.6 million people were treated for schistosomiasis in 2014 (WHO, 2016). Urinary Schistosomiasis affects people in developing countries particularly children who acquire the disease during recreational activities in snailinfested water (Bello et al., 2002).Transmission can take place in almost any type of habitat, from large lakes or rivers to small seasonal ponds or streams (WHO, 2002), through contact with contaminated water while performing daily chores such as washing, laundry, fetching water and herding animals. With each passing year a child's risk of infection increases peaking between the ages of 10 and 20 (Kabaterine, et al., 2004). It has recently been estimated that school-aged children experience a considerable burden of schistosomiasis which may have both immediate and long-term consequences on their health, growth and education (Ekpo et al., 2011, Houmsou et al., 2012).In Sub-saharan Africa $S$ haematobium infection is estimated to cause 70,32, 18 and 10 million cases of haematuria, dysuria, bladder wall pathology and major hydronephrosis respectively (Ven der Werf et al., 2003). The prominence of infection is attributed to poor environmental sanitation and inadequate access to safe tap water; these conditions lead to continued exposure to the infective stages of the parasite and thus high rates of re-infection (Catherine et al., 2003; A kinboye et al., 2011).

Nigeria is one of Africa's most severely affected countries with an estimated 101.28 million people at risk of the infection while 25.83 million are already infected (Chitsulo et al., 2000) but it has been unsystematically reported and large areas remain where the disease status is unknown (Anosike et al., 2001). In Nigeria schistosomiasis is endemic in 34 of the 36 states and Abuja (Steinman, 2006; Opara et al., 2007). Urinary schistosomiasis is widespread in both rural and urban communities in Nigeria with prevalence ranging between $2 \%$ and $90 \%$ and the vast majority of cases occuring among the poor and marginalised. Since schistosomiasis was found to have severe effects on cognitive, physical and intellectual growth as well as nutritional deficiencies among school aged children this study aimed to investigate the presence of urinary schistosomiasis among primary school children in
Fallau, Danbagina and Gano primary schools. The results could be used to improve planning, implementation, monitoring and evaluation of Urinary Schistosomiasis interventions in the area.

\section{Material and methods Study Area}

This study was conducted in Falau, Gano 2 and Danbagina primary schools in Dawakin kudu Local Government Area of Kano state, Nigeria. Dawakin Kudu Local Government Area has an area of $384 \mathrm{~km}^{2}$. It is located between latitude $11.811^{\circ} \mathrm{N}$ and longitude $8.78^{\circ} \mathrm{E}$ and bordered to the north-west by Madobi and Kumbotso local government areas, to the north-east by Warawa Local Government Area, to the south-east by Wudil Local Government Area, to the south by Bunkure Local Government Area, and to the south-west by Kura Local Government Area.

These three schools are few kilometers to Gano town and about $10 \mathrm{~km}$ from the fishing community of Panchan. The Falau primary school is located few meters away from Falau pond, the school mainly separated from the pond by road to Fallau village. Gano and Danbagina are very close to a part of Wudil River. The occupation of the people of these three villages are mainly farming and fishing, their main crops are sweet potato, maize, millet, rice, groundnut, sugar cane and beans.

\section{Study design}

Permission to conduct the study was obtained from the Education Secretary (ES) State Universal Primary Education Board (SUPEB).The selected schools were visited before sample collection, the school authorities, teachers, and children were briefed on the purpose and benefit of the study. All those who participated in the study gave informed consent before they were enrolled. They were also allowed time to discuss and obtain permission of their parents.

\section{Questionnaire Design}

Questionnaire was used to collect information such as age, sex, symptoms, treatment, name (codes given), level of awareness and water contact activities such as swimming, fishing, playing/bathing, irrigation, and rice farming etc. in lakes, rivers, ponds or rain fed pools. During administration of questionnaire, the children were interviewed individually during which the class teachers assisted in the interpretation (from English to the local language (Hausa) and filled the questionnaire for those of them that cannot do it by themselves.

Each child was then provided with a pre- 
labelled, wide-mouthed, screw capped $20 \mathrm{ml}$ plastic container for the collection of mid-day urine sample between $11 \mathrm{am}-1 \mathrm{pm}$. The sealed sample containers containing the urine were placed inside the storage flask containing ice packs. The samples were immediately transported to the laboratory in Biological sciences Department, Nigeria Police Academy, Wudil, Kano for analysis.

\section{Macroscopic examination}

The urine samples collected were carefully examined for haematuria.

\section{Parasitological examination of urine}

$10 \mathrm{ml}$ of urine was centrifuged at $5000 \mathrm{rpm}$ for 5 minutes to concentrate the eggs of the schistosome. After centrifugation, the upper layer (the supernatant) was discarded, the sediment left was deposited gradually by drops using a Pasteur pipette on a clean grease-free glass slide and carefully covered with a cover slip. The slide was then mounted on a light microscope and examined using ax40 objective for the eggs of $S$ haematobium characterized with a terminal spine (Ekpo etal.,2011).

\section{Data Analysis}

The data obtained were statistically analyzed using Chi square-test with a p-value of 0.05 and simple percentage to obtain prevalence.

\section{Results}

The result of this study was presented in tables and indicates that Urinary schistosomiasis is present in all the schools screened from the three villages. Of the 320 samples examined an overall prevalence of $34(10.6 \%)$ was recorded. Fallau recorded the highest prevalence with 11(16.92\%)followed by Gano II, $14(10.37 \%)$ ) while Danbagina recorded the least $9(7.5 \%)$. The age group with the highest prevalence is $8-10,13$ $(15.85 \%)$ and that with the least infection was the $5-7,1(4.55 \%)$ age group. Males have higher prevalence $26(12.1 \%)$ compared to females, $8(7.7 \%)$. Females within the age range 5-7 were not infected. Statistically, there wasa significant difference in infection among the different villages from which the pupils came from $\left(\chi^{2}=8.94\right.$, d.f $=2, p$-value $\left.<0.05\right)$, there was also a significance difference in infection among the different age groups examined, $\chi^{2}=2.9356, \mathrm{df}=$ $3, \mathrm{p}<0.05$.

Table 1: Prevalence of urinary schistosomiasis according to sex in the study area

\begin{tabular}{|c|c|c|c|c|c|c|c|c|}
\hline \multirow{2}{*}{$\begin{array}{l}\text { Sampling } \\
\text { Site }\end{array}$} & \multicolumn{2}{|l|}{ Male } & \multicolumn{2}{|l|}{ Female } & \multicolumn{2}{|l|}{ Total } & \multicolumn{2}{|l|}{ Intensity (\%) } \\
\hline & $\begin{array}{l}\text { No. } \\
\text { Examined }\end{array}$ & $\begin{array}{l}\text { No. and } \\
\% \\
\text { infected }\end{array}$ & $\begin{array}{l}\text { No. } \\
\text { Examined }\end{array}$ & $\begin{array}{l}\text { No. and \% } \\
\text { infected }\end{array}$ & $\begin{array}{l}\text { No. } \\
\text { Examined }\end{array}$ & $\begin{array}{l}\text { No. and } \\
\% \text { infected }\end{array}$ & $\begin{array}{l}\text { Light intensity } \\
(<50 \text { eggs } / 10 \mathrm{ml})\end{array}$ & $\begin{array}{l}\text { Heavy } \\
\text { intensity } \\
(<50 \\
\text { eggs } / 10 \mathrm{ml}\end{array}$ \\
\hline Gano 2 & 96 & $12(12.5)$ & 39 & $2(5.1)$ & 135 & $14(10.37)$ & $14(28)$ & 0 \\
\hline Fallau & 29 & $7(24.13)$ & 36 & $4(11.1)$ & 65 & $11(16.92)$ & $11(22)$ & 0 \\
\hline Danbagina & 90 & $7(7.8)$ & 30 & $2(6.7)$ & 120 & $9(7.5)$ & $9(18)$ & 0 \\
\hline Total & 215 & $26(12.1)$ & 105 & $8(7.7)$ & 320 & $34(10.63)$ & $34(10.63)$ & 0 \\
\hline
\end{tabular}

$\left(\chi^{2}=8.94\right.$, d.f $=2$, p-value $\left.>0.05\right)$

Table 2: Prevalence of $S$. haematobium infection with respect to age

\begin{tabular}{|c|c|c|c|c|c|}
\hline \multirow[b]{2}{*}{$\begin{array}{l}\text { Age group } \\
\text { (Years) }\end{array}$} & \multirow[b]{2}{*}{$\begin{array}{c}\text { No. } \\
\text { Examined }\end{array}$} & \multirow[b]{2}{*}{$\begin{array}{l}\text { No. and \% } \\
\text { infected }\end{array}$} & \multicolumn{3}{|c|}{ Intensity (\%) } \\
\hline & & & $\begin{array}{c}\text { No. } \\
\text { Examined }\end{array}$ & $\begin{array}{l}\text { Light intensity } \\
(<50 \text { eggs } / 10 \mathrm{ml} \text { of } \\
\text { urine })\end{array}$ & $\begin{array}{c}\text { Heavy intensity } \\
(<50 \text { eggs } / 10 \mathrm{ml} \text { of } \\
\text { urine })\end{array}$ \\
\hline $5-7$ & 22 & $1(4.55)$ & $1(4.55)$ & 0 & \\
\hline $8-10$ & 82 & $13(5.85)$ & $13(5.85)$ & 0 & \\
\hline $11-13$ & 156 & $15(9.61)$ & $15(9.61)$ & 0 & \\
\hline $14>$ & 60 & $5(6.66)$ & $5(6.66)$ & 0 & \\
\hline Total & 320 & $34(10.63)$ & 10.63 & 0 & \\
\hline
\end{tabular}

\section{Discussion}

The observed prevalence of urinary schistosomiasis in the study area was very low, 34 (10.6\%) compared to findings from elsewhere in the state and Nigeria as a whole that have predisposing factors for the disease. This prevalence is lower than $37.1 \%$ reported by Hemabo and Omudu (2015) in Benue state;
Ukatuet al, (2015) in Kebbi state and $12.7 \%$ by Sam - Wobo et al (2015) in Ogun state. Danbagina and Fallau are very close to Wudil River and Fallau is very close to Ungurgu pond (the pond is just about two minutes' walk to the school). Gano primary school was also located very close to the pond where constant water contact activities are taking place. An overall prevalence of $10.6 \%$ 
justifies the need for further epidemiological studies in the area. The prevalence rate observed in this study is lower than obtained in previous studies in other parts of Kano state like in Wasai, in Minjibir Local Government Area (Duwa, et al.,2009) but higher than what Dawakiet al., (2015) reported from five Local Government Areas collectively in the state. The low prevalence constitutes a public health problem as it could rise unless curtailed early and this also may not reflect the true rate of infection in the area. The level of infectivity of the pupils showed that males recorded higher infection when compared to females. This observation agrees with other reports made earlier, such as that of Sam-woboet al., (2015) that males are more infected with S.haematobium because males are more involved in water contact activities. In this study children above the age of 14 years had less cases of the infection. Nworie (2012) opined that the decline of prevalence among older children in some population is due to a decreased contact with infested water and the possible development of concomitant immunity common to schistosomiasis. Development of immunity may be the best explanation here as older children are found to be highly involved in fishing in the fishing communities of Kano state. The fact that different new species of the intermediate host (Bulinus) are emerging seems to worsen the situation (Duwa, 2018).

\section{References}

Adulugba, A O and Omudu, E A. (2015): Epidemiological Studies on some parasitological and Ecological aspects of schistosomiasis in Agatu, Benue state. Nigeria Journal of Parasitology Vol. 36(1)

Akinboye, D O., Ajishebutu, J U., Fawole,O., Agbolade,O M., Amosu A M., Atulomah, N OS.,

Awodele, O., Oduola, O., Owodunni, B M., Rebecca, S N., Falade, $\mathrm{M}$ and Emem, O. (2011). Urinary schistosomiasis: Water contact frequency and infectivity among Secondary school students in Ibadan Nigeria. Nigerian Journal of Parasitology 32(1) 129-134

Anosike, J .C.,Nwoke, B.E.B and Njoku, A .J. (2001). The validity of haematuria in the community diagnosis of urinary schistosomiasis infection. Journal of Helminthology 75(3):223-225

Anosike, J C., Oguwuike, U T., Betram, E B., Asor, J E., Ipeama C A., Nwosu, D C and Ogbusu,

F I. (2006).Studies on Vesicalschistosomiasis among rural Ezza farmers in the south western border of Ebonyi state, Nigeria. Ann Agric Environ Med.13:13-19

Bello, A.B., and Edungbola, L.D. (2002). Common parasite disease in childhood in Nigeria. Incidence and intensity of infection: Tropical Parasitology. 3:9-11 Journal of Biomedical Research.5: 103107.

Catherine, M., Scott, W. and Gordon, M.R. (2003). The Global Burden of the Disease Due to Schistosomiasis. DPP Working Paper 19, WHO, Bow Street, Cambridge, Massachusetts.

CDC (2004). BMI About children and Teens http://en.wikipedia.org/wiki/body massindex

Chitsulo L., Engels D., Montresor A., and Savioli L. $(2000)$. The global status of schistosomiasis and its control. Acta Trop 77: 41-51.

Dawaki, S., Hesham M., AlmekhlafiInitIthoi., Jamaiah, I., AwatifM.Abdulsalam and Abdulhamid A. (2015). The Menace of Schistosomiasis in Nigeria: Knowledge Attitude and Practices regarding Schistosomiasis among Rural Communities in Kano State PLoS ONE 10(11)

Duwa, M. R., Oyeyi, T I and Bassey, S E. (2009). Prevalence and Intensity of Urinary schistosomiasis among children in Minjibir Local Government Area. Bayero Journal of Pure and Applied Sciences (BAJOPAS) 2: 75-78

Duwa, S. R. (2018). Current status of Lymnea and Bulinus species in Wasai part of Jakara dam, Kano state, Nigeria and their public health implications. International Organization of Scientific Research 13 (1) pp5-8

Ekpo, U., Vounatsou, P., Huerlimann, E., Utzinger, J., Mafiana, C., Mafe, M., Oluwole, A., Abel, M., Nebe, O and Kadiri, M. (2011).Journal of Epidemiology and Community Health 2; 65, A447 Doi; 10; $142976 \mathrm{p} 45$

Hemabor, O.M and Omudu, E.A. (2015). Epidemiological studies on Urinary schistosomiasis among school children in Makurdi, Benue state. Nigerian Journal of Pure and Applied Sciences Vol.7: p46-53

Houmsou, R. S., Amuta, E.U and Sar, T.T. (2012). Profile of an Epidemiological study of Urinary schistosomiasis in two local government areas of Benue stat, Nigeria. International journal of Medicine and Biomedical Research 1:39-48

Kabaterine, N.,Brooker, S and Tta-hebwa,E. (2004). Epidemiology and Geography of $S$ 
mansoni in Uganda: Implications for planning. Tropical Medicine and International Health, 9:370-380

Nworie, O., Nya, O., Anyim, C., Okoli, C. S and Okonkwo, E.C. (2012). Prevalence of Urinary schistosomiasis among primary school children in Afikpo North Local Government Area of Ebonyi state. Annals of Biological Research, 3 (8):3894-3897

Odaibo, A.B., Adewumi, C., Olorumola, F.O., Ademoyin, C.O. Olofintoye, L.K., Akinwumi, T.A., Adetula, M.O., Awe, C.O. and Akinyemi, F. (2004). Preliminary studies in the Prevalence and distribution of urinary schistosomiasis in Ondo State, Nigeria. African Journal of Medical Science, 33 (3): 219-224.

Omudu, E.A., Onah, E. and Emberga-Biem, M. (2012). Epidemiological studies of polyparasitism in two different communities in Benue State, Nigeria. Journal of King AbdulazizUniversity. Medical Sciences, 19(1):21-34.

Opara, K.N., Udoidung, N. I and Ukpong, I.G. (2007). Genito-urinary schistosomiasis among pre-Primary school children in rural community within the Cross River Basin, Nigeria. Nigeria Journal of Helminthology, (81):393-394

Sam-wobo,S.O., William, M., Egbeobauwaye, E., Suraka,O. A and Adekunle, O.N. Urinary schistosomiasis among school age children in Odeda Local Government Area of Ogun state. Nigerian Journal of Pure and Applied
Science. 7:71-74

Steinman,P., Keiser, j., Bos, R., Tanner, $M$ and Utzinger, J. (2006). Schistosomiasis and Water Resources development: Systematic Review, Meta- analysis and estimates of people at risk. Lancet Infectious Diseases. 6:411-425

Stephenson L. (1993). The impact of schistosomiasis on human nutrition. Parasitology. Vol.107:107-23

Ukatu, V.E., Yahaya, S., Yaye, A.S., Shabandan, B. S and Attah, O.A. (2015). Urinary schistosomiasis in Yauri riverine area, Nigerian Journal of Parasitology Vol.36 (2), 77-80

Utzinger, J., N'Goran, E K., Caffrey, C R and Keiser, J. (2011). From innovation to application: Socio-ecological context, diagnostic, drugs and integrated control of schistosomiasis, Actatropica, 120: 121-137

Van der Werf M.J., de Vlas S.J., Brooker S., Looman C.W., Nagelkerke N.J and Habberma J.D. (2003). Quantification of clinical morbidity associated with schistosome infection in Sub-Saharan Africa. ActaTropica Vol. 86 (2-3):125-39

World Health Organization. (2002). Prevention and control of Schistosomiasis and soil transmitted helminthiasis. WHO Technical report series, No. 912: i-vi. 1-57 Geneva

World Health Organization Schistosomiasis Fact Sheet. (2016). Number 115 Available at http://www.who.int/mediacenter/fact sheets/fs115/en/index.html 